\title{
Decision support system for individual athlete's diet based on optimization modeling' development
}

\author{
Igor Kotciuba ${ }^{1, *}$, Evgenii Ermakov ${ }^{1}$, and Alexey Shikov ${ }^{2}$ \\ ${ }^{1}$ ITMO University, 197101, Kronverksky Av., 49, Saint Petersburg, Russia \\ ${ }^{2}$ Russian Academy of National Economy and Public Administration under the President of the \\ Russian Federation (North-West Institute of Management - a branch of RANEPA), 199178, Sredny \\ prospect V.O., 57/43, Saint Petersburg, Russia
}

\begin{abstract}
The article discusses the main areas of information technology tools application in the training of athletes, analyzes the types of expert systems that can be applied for this subject area, indicating the features of their use, including the tasks of supporting the plans preparation for individual diets of athletes. The formulated mathematical model is considered as a decision-making model in an optimization formulation for seeking the optimal ratio of food components from the space of admissible decisions of the various food products ratio. The recommendations regarding the daily needs of athletes in the necessary vital components for various sports activity categories, considering the norms of daily calorie intake in accordance with the Mifflin-San Geor formula, indicating the maximum norms of proteins, fats, carbohydrates, are analyzed. A mathematical model is presented in an optimization formulation from the class of discrete programming, on which the developed intelligent decision support system is based. The implementation components of the software system in the pseudocode format and examples of the implementation of the model for the formation of individual diet plans in the optimization setting are presented. The developed software package can be used for automatic generation of basic recommendations for the proposal of individual diets as an auxiliary means of supporting the activities of a dietitian to find the optimal plan in terms of maximizing individual preferences for food in the area of permissible values for the restrictions on the type of sports activities and the maximum norms of food components.
\end{abstract}

\section{Introduction}

The modern field of sports is characterized by increased individualization and attention to the needs of both an athlete performing in individual competitions and as part of a group. As studies show [1], the effectiveness of sports is significantly increased due to the development of training programs, taking into account individual physiological needs,

\footnotetext{
${ }^{*}$ Corresponding author: igor.kotciuba@gmail.com
} 
operational control over the physiological state of athletes, which increases the reliability and information content of the preparation process for competitions.

A large array of data, including personal information about the athlete, as well as data on the training process, actualizes the issue of using problem-oriented information technologies to solve various problems in the sports sphere. Among the main directions of using information technologies in this subject area, the following can be distinguished [2]:

1. Computer diagnostics, testing, control and results evaluation.

2. Comprehensive control of the body state, analysis of factors contributing to an increase in the training effectiveness $[3,4]$.

3. Assessment of load parameters, sports form and limiting capabilities of the organism.

4. Monitoring and adjustment of the training program for athletes [5-7].

5. Systematization, storage and analysis of incoming information about the training process [8].

6. Analysis of biometric data with further construction of 3D-models of a set of exercises [9].

One of the specific tasks encountered in the process of training an athlete is the diet choice and the composition of a nutrition suitable for the type of activity, taking into account individual physiological characteristics. Among the problems raised in studies on this topic, the following can be distinguished:

1. The correct selection of vitamins, microelements, as well as the need to find the optimal proportions of carbohydrates, fats, proteins.

2. The need to keep track of calories, meal schedules, taking into account the goal of training, physique and daily calorie requirements.

3. Special recommendations on the content of proteins, carbohydrates, etc. for activities with increased physical activity [10-12].

In works [13-14], approaches to the development of information technologies are considered in relation to the issues of drawing up an athlete's diet. Among the functional features of existing developments are such as:

1. Calculation of the optimal body weight based on indicators of age, weight, height with the selection of a special diet.

2. Analysis of the composition of nutrition components of consumed food in real time.

3. Tracking the diet, both in general and in individual details.

Automation often covers not only the issues of computer modeling of the training process and the calculation of basic nutritional indicators, but also more complex tasks collecting and analyzing data from various experts, interpreting expert knowledge, making managerial decisions, forecasting, which means it updates the process of developing more complex information systems related to the categories of advisory systems, automated control systems, decision support systems, etc. With regard to the specifics of sports activity, one can single out such existing information technologies as [15-16]:

1. Expert systems of knowledge objectification regarding nutrition and other sports analytics.

2. Expert systems for decision support using machine learning methods for monitoring and interpreting a large number of indicators of various categories (including sociopsychological, biochemical, pedagogical, medico-biological) in the knowledge base, implemented using web technologies.

3. Database on the accounting of physical, tactical, technical, functional training of an athlete with further system analysis.

4. Computer programs for calculating the athlete's need for various food components, determining the medico-biological requirements for completing the diet, as well as a program for calculating and selecting a suitable diet. 
Based on the above, it can be highlight the specifics of information systems use in the field of sports, with its division into different classes according to the nature of data processing. The analysis summary results are shown in Table 1.

Table 1. Classification of information systems functions in sports by the nature of data processing.

\begin{tabular}{|c|c|}
\hline $\begin{array}{l}\text { Informational and referencial } \\
\text { (searching) Information systems }\end{array}$ & $\begin{array}{l}\text { Information processing systems } \\
\text { (decisive IS) }\end{array}$ \\
\hline $\begin{array}{l}\text { Computer testing, results control. } \\
\text { Database for the registration of physical, } \\
\text { tactical, technical, functional training of an } \\
\text { athlete. } \\
\text { Complex control of the body state. } \\
\text { Storage of parameters of activity, fitness } \\
\text { and limiting capabilities of the body. } \\
\text { Training program monitoring for athletes. } \\
\text { Systematization, storage of incoming } \\
\text { information about the training process. } \\
\text { Building 3D models of a set of exercises. } \\
\text { Tracking the diet, both in general and in } \\
\text { individual details. } \\
\text { Track the nutrition schedule based on } \\
\text { specific training goal, physique, and daily } \\
\text { calorie requirements. } \\
\text { Analysis of the food components } \\
\text { composition of consumed food in real time. } \\
\text { Computer programs for calculating the } \\
\text { athlete's need for various food components. }\end{array}$ & $\begin{array}{l}\text { Computer diagnostics, testing, evaluation of } \\
\text { results. } \\
\text { Analysis of factors contributing to an increase in } \\
\text { the effectiveness of training. } \\
\text { Assessment of parameters of activity, sports form } \\
\text { and limiting capabilities of the organism. } \\
\text { Correction of the training program for athletes. } \\
\text { Incoming information analytics about the training } \\
\text { process. } \\
\text { Analysis of biometric data. } \\
\text { Technologies for finding the optimal proportions } \\
\text { of carbohydrates, fats, proteins. } \\
\text { Calculation of the optimal body weight based on } \\
\text { indicators of age, weight, height with the } \\
\text { selection of a special diet. } \\
\text { Expert systems for objectifying knowledge } \\
\text { regarding nutrition and other sports analytics. } \\
\text { Expert systems for decision support using } \\
\text { machine learning methods for monitoring and } \\
\text { interpreting a large number of indicators of } \\
\text { various categories. } \\
\text { Computer programs for calculating and selecting } \\
\text { a suitable food }\end{array}$ \\
\hline
\end{tabular}

Thus, it can be concluded that not only information and reference systems, but also technologies to support medical decision-making, requiring formalization and interpretation of medical knowledge, are actively developing at present time. It should be also mentioned that in training athletes it is crucial to use specialized information technologies based on mathematical modeling and analysis of a variety of expert opinions (medical workers, head coach, psychologist, support staff), which requires the development of innovative technologies. Nevertheless, the analyzed works do not pay due attention to the detailed description of mathematical models for the formation of an athlete's diet, and also do not give recommendations on formalizing the individual preferences of an athlete for various product categories and do not consider methods for solving the problem of forming a diet plan in an optimization setting with the choice of the best alternative solution space, which makes the task of developing such a problem-oriented solution urgent.

\section{Materials and methods}

Based on the analysis of the subject area, we can conclude that the automation of creating an individual diet plan process will significantly reduce the labor intensity and time of the athlete and trainer involved in drawing up the diet plan, and will also allow for better calculation of the necessary food components, taking into account individual preferences.

- There are various approaches to calculating calorie norms for a diet plan. As an example for calculating the daily rate of kcal. the Mifflin-San Geor formula was used [1718], which allows to formalize the norms of calorie content taking into account gender, weight, height, age. 
- To develop a support system for creating an individual diet plan, it is necessary to consider the basis of the diet for athletes [19]:

- proteins of animal origin;

- proteins of vegetable origin;

- fats of animal and vegetable origin;

- vegetable fiber.

- During the review of the subject area, it was revealed that in order to meet the nutritional needs of an athlete, it is necessary to adhere to the ratio of proteins - fats carbohydrates in an appropriate proportion of $15 \%-30 \%-55 \%$ of the daily caloric intake of food.

- There are the following recommendations regarding the daily requirement of athletes for the necessary vital components [20]:

- 1.2-1.4 $\mathrm{g}$ of protein per $\mathrm{kg}$ of body weight for athletes, if their physical activity is aimed at increasing strength endurance;

- 1.6-1.7 $\mathrm{g}$ of protein per kg of body weight if it is necessary to increase muscle mass;

- up to $2 \mathrm{~g}$ of protein per $\mathrm{kg}$ of body weight for athletes whose activities are associated with increased strength loads;

- 1.3-1.5 g of vegetable proteins per $1 \mathrm{~kg}$ of body weight during work that is not designed for heavy physical labor, and in the case of heavy physical work, it is recommended from 2 to $2.5 \mathrm{~g}$ of proteins per $1 \mathrm{~kg}$ of body weight.

The information obtained at this stage is entered into the database of athletes, which allows further calculation of the individual needs of athletes in all nutrients. The database model is shown in Fig. 1. A distinctive feature of the database is the storage of information about food products, food components contained in them and the athlete's preferences (conditional coefficient of ranking the priority of a food product):

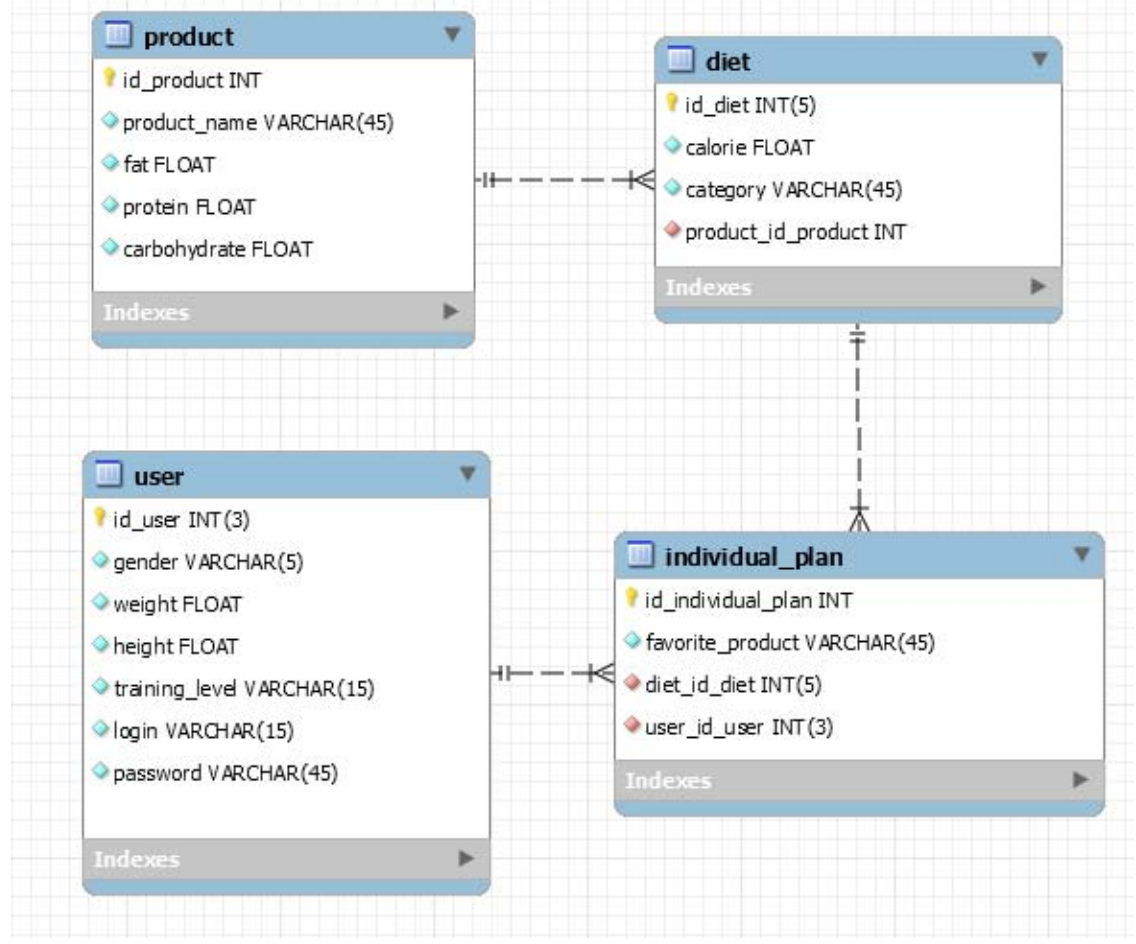

Fig. 1. Database model. 
Based on the analysis of the subject area and a review of similar solutions, the general functionality of the system being developed was formed:

- registration with indication of personal data;

- authorization by credentials;

- editing of user's personal data in the account settings;

- formation of a diet based on user preferences;

- viewing the user's personal data in the account overview;

- viewing information about diet;

- editing the diet plan by changing personal data.

To solve the problem of developing an intelligent system for supporting the composition of a diet for an athlete, a class of discrete optimization programming methods was chosen with fixing restrictions on food components in a mathematical model (B1 ... $\mathrm{B} 4)$, fixing the specific ratio of food components in specific food products $(\mathrm{P} 1, \ldots, \mathrm{Pn})$ and user preferences for the consumption of these components $(\mathrm{C} 1 \ldots \mathrm{C} 4)$ as an objective function. To solve the discrete programming problem, the Gomori algorithm was chosen with additional constraints - the function of correct cutoffs to obtain the optimal integer result.

- The mathematical model underlying the software package is presented below:

- $\mathrm{Cn}$ - product importance factors.

- B1 - minimum amount of proteins per day.

- B2 - minimum amount of fats per day.

- B3 - minimum amount of carbohydrates per day.

- B4 - calorie content.

$0,12 \mathrm{~m} \leq b_{1} \leq 0,014 \mathrm{~m}$ (in case of strength endurance);

$0,016 \mathrm{~m} \leq b_{1} \leq 0,017 \mathrm{~m}$ (in case of an increase in muscle mass);

$b_{1} \geq 0,02 \mathrm{~m}$ (in case of large power loads);

$0,02 \mathrm{~m} \leq b_{1} \leq 0,025 \mathrm{~m}$ (in case of hard physical work);

Table 2. Example of data of the service mathematical model.

\begin{tabular}{|c|c|c|c|c|}
\hline $\begin{array}{l}\text { The product's } \\
\text { name }\end{array}$ & Proteins & Fats & Carbohydrates & Calorie content \\
\hline П1 (x1) & a11 & a12 & a13 & a14 \\
\hline$\Pi 2(\mathrm{x} 2)$ & $\mathrm{a} 21$ & a22 & a23 & a24 \\
\hline$\Pi 3(\mathrm{x} 3)$ & a31 & a32 & a33 & a34 \\
\hline & & & $\ldots$ & $\ldots$ \\
\hline$\Pi n(x n)$ & an & an & an & an \\
\hline
\end{tabular}

$$
b_{1}=0,15 b_{4} ; b_{2}=0,3 b_{4} ; b_{3}=0,55 b_{4}
$$

$$
\begin{gathered}
F(x)=C_{1} x_{1}+C_{2} x_{2}+C_{3} x_{3}+\cdots+C_{n} x_{n} \rightarrow \max \\
D=x \in R^{n}\left\{\begin{array}{c}
a_{11} x_{1}+a_{21} x_{2}+a_{31} x_{3}+\cdots+a_{n 1} x_{n} \geq b_{1} \\
a_{12} x_{1}+a_{22} x_{2}+a_{32} x_{3}+\cdots+a_{n 2} x_{n} \geq b_{2} \\
a_{13} x_{1}+a_{23} x_{2}+a_{33} x_{3}+\cdots+a_{n 3} x_{n} \geq b_{3} \\
a_{14} x_{1}+a_{24} x_{2}+a_{34} x_{3}+\cdots+a_{n 4} x_{n} \geq b_{4} \\
x_{1}+x_{2}+x_{3} \leq 15 \\
x_{1}, x_{2}, x_{3} \geq 0
\end{array}\right.
\end{gathered}
$$

The presented mathematical model allows one to obtain the optimal diet plan as a vector of the corresponding food components $\mathrm{x} 1, \ldots, \mathrm{xn}$ - food multiples of $100 \mathrm{~g}$ (from the point of view of the maximum individual preferences of an athlete for food) from the space of admissible solutions (taking into account medical restrictions on nutrition). Due to the 
functionally adjustable parameters, automation tools allow one to change the limit values of $\mathrm{kcal}$, if not using the Mifflin-San Geor formula, but other recommendations for additional medical recommendations regarding the athlete's nutrition.

In fig. Figures 2-4 the models for the detailed design of an athlete's diet support system are shown:

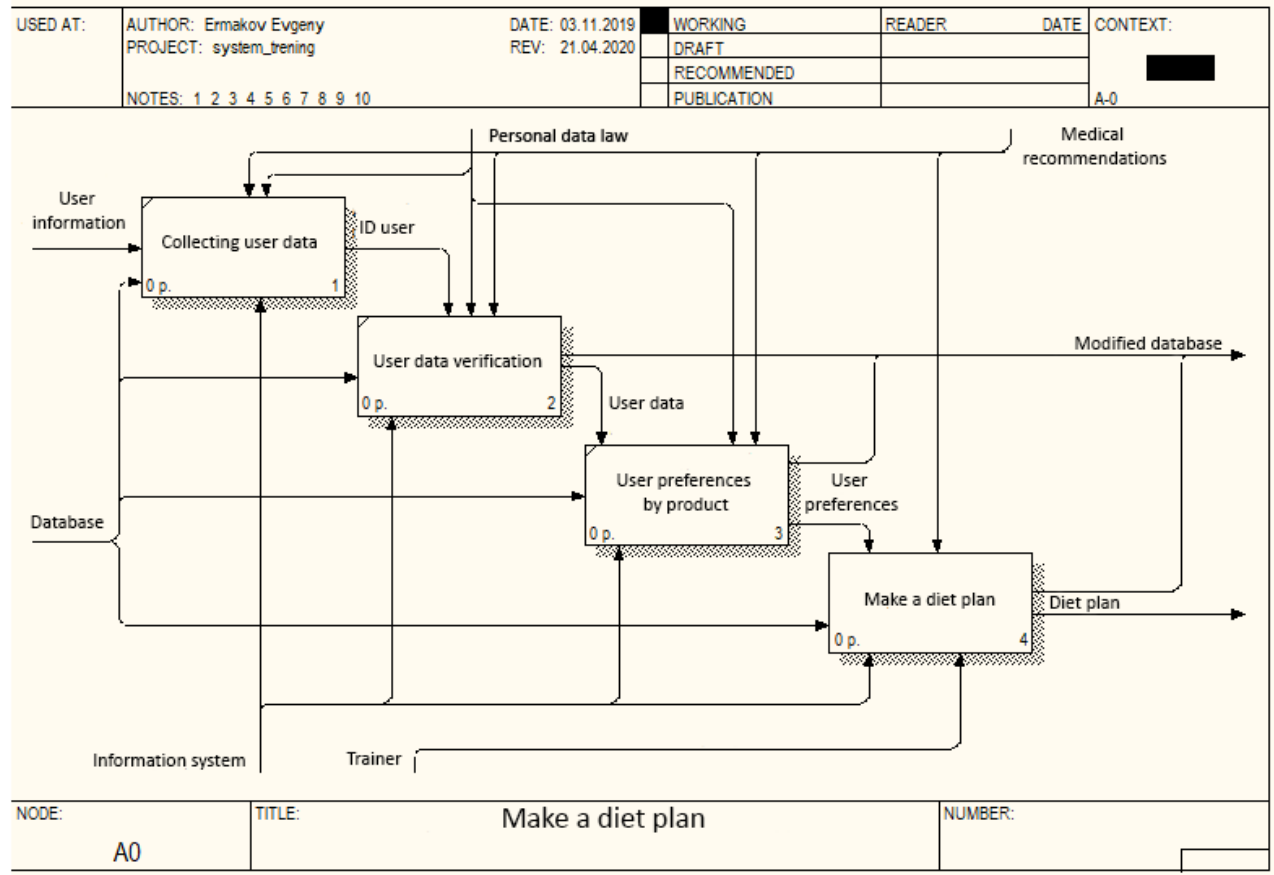

Fig. 2. Functional model of the diet formulation process.

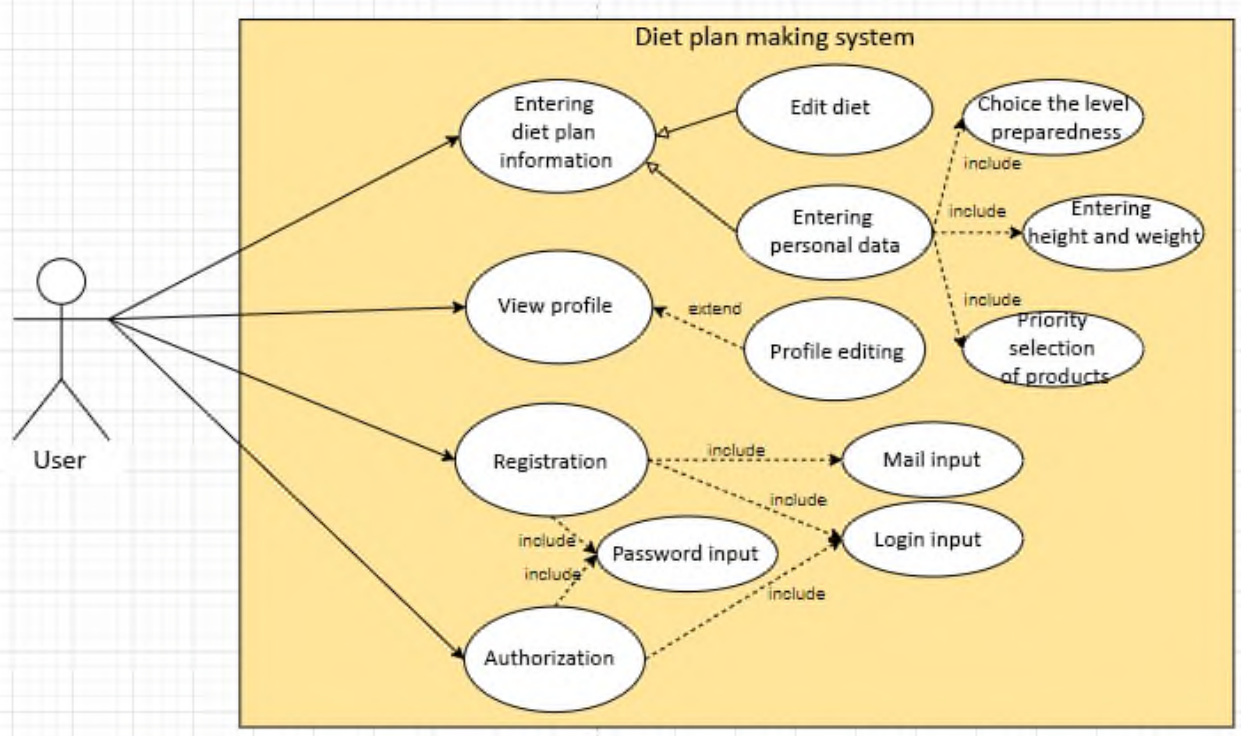

Fig. 3. Variants of using the system by the user. 


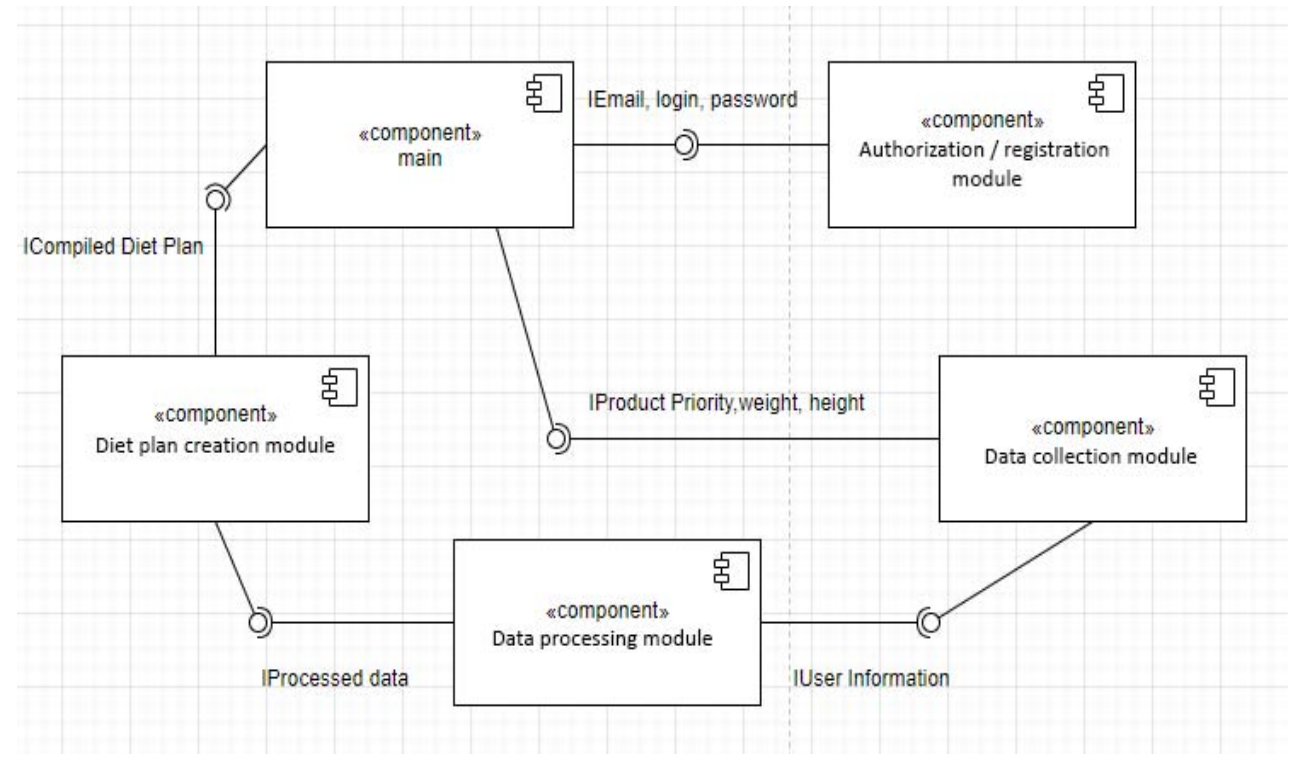

Fig. 4. System architecture of the information system.

The presented models of the information system make it possible to unambiguously describe the logic of its technical presentation and precede the stage of software implementation.

\section{Results}

The following technology stack was used to implement the system:

- programming language PHP 7;

- programming language Java Script;

- jQuery library for Java Script;

- layout language HTML 5;

- cascading style sheets (CSS 3).

The implementation of the main functions of the decision support system is presented in pseudocode format:

function NormCcal() \{

var num1, num2, num3, num4, num5, result;

num1 = document.getElementById('weight').value;

num1 $=$ parseFloat(num1);

num2 = document.getElementById('height').value;

num2 = parseFloat(num2);

num3 = document.getElementById('years').value;

num3 = parseFloat(num3);

num4 = document.getElementById('gender').value;

num4 $=$ parseFloat(num4);

num5 = document.getElementById('active').value;

num5 $=$ parseFloat(num5);

result $=((9.99 *$ num 1$)+(6.25 *$ num 2$)-(4.92 *$ num 3$)-$ num 4$) *$ num5;

var out $=$ document.getElementById('out');

out.value $=$ result;

\} 
function calcularSimplex() \{

let calculosabela = document.getElementById("calculat")

calculosabela.innerHTML $="$

$\mathrm{NLP}=[]$

nTabelas $=0$

otima $=$ false

while (!otima) \{

findcolumn ()

recalcularTabela()

if (CheckSolutions ()) \{

otima $=$ true

showTable () $\}$ \} $\}$

Examples of the formed diet plan are shown in Fig. 5-6.

\section{Instructions}

1. Enter your individual data (weight, height, fitness level, type of load).

2. Select priority products.

3. Enter from 1 to 10 how much you like the product.

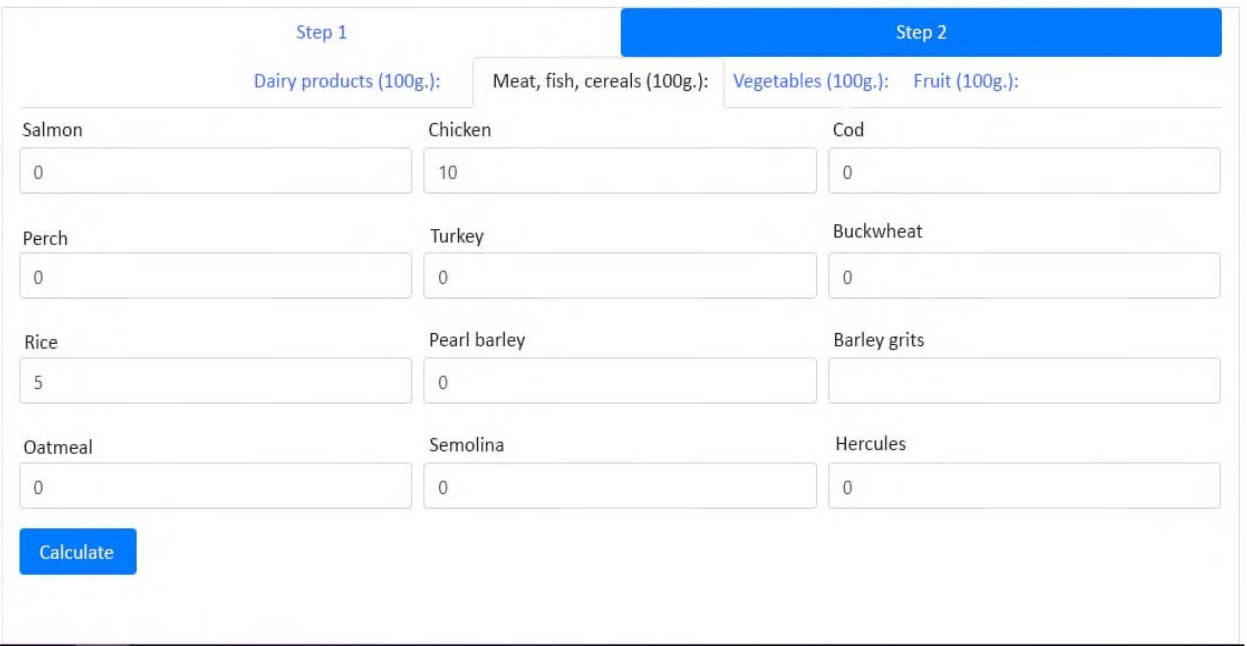

Fig. 5. Form for entering the individual preferences of an athlete for food. 


\begin{tabular}{ll}
\hline Calculate & \\
\hline Show & \\
\hline Priority products & Won-priority products \\
\hline Chicken $=313$ rрaмм/Mn $=0$ & Baked millk $=0$ \\
Rice $=241$ грамм/Mn & Milk $=0$ \\
\hline & Cheese $=0$ \\
& Yogurt $=0$ \\
\hline & Sour cream $15 \%=0$ \\
& Kefir $=0$ \\
\hline & Curd $9 \%=0$
\end{tabular}

Fig. 6. Recommended diet plan.

\section{Discussion}

The presented solution makes it possible to simplify the development of a high-quality nutrition program, taking into account medical recommendations on the necessary limit values of food components required when engaging in various types of physical activity, as well as to take into account the individual preferences of an athlete for the consumption of various categories of products containing these food components. A distinctive feature of the developed system is its intellectual component, which makes it possible to support decision-making in an optimization setting.

\section{Conclusions}

The paper analyzes the existing information systems in the training of athletes and makes a conclusion about the specificity of their classification by the nature of data processing; approaches to automating the process of developing an individual diet plan for an athlete are presented. The development of such a plan requires a lot of time and constant involvement of an expert in sports nutrition, and is also generally characterized by the issuance of basic recommendations without taking into account the individual approach to the athlete. Automatic selection of the limiting values of food components, recommended by an expert depending on the type of physical activity, as well as automatic formation of a diet plan in an optimization setting, considering individual preferences set by an athlete, will significantly reduce the complexity of organizing the process.

\section{References}

1. J.B. Barker, M.J. Slater, G. Pugh, S.D. Mellalieu, P.J. McCarthy, M.V. Jones, A. Moran, The effectiveness of psychological skills training and behavioral interventions in sport using single-case designs: A meta regression analysis of the peer-reviewed studies, J. Psychology of Sport and Exercise 51, 101746 (2020) doi: https://doi.org/10.1016/j.psychsport.2020.101746 
2. V. Ratten, Sport technology: A commentary, The Journal of High Technology $\begin{array}{llllll}\text { Management } & \text { Research } & 31 & (1), & 100383 & \text { (2020) doi: }\end{array}$ https://doi.org/10.1016/j.hitech.2020.100383

3. P. Millar, J. Stevens, Management training and national sport organization managers: Examining the impact of training on individual and organizational performances, J. Sport Management Review 15 (3), 288-303 (2012) doi: https://doi.org/10.1016/j.smr.2012.01.003

4. A. Rapp, L. Tirabeni, Self-tracking while doing sport: Comfort, motivation, attention and lifestyle of athletes using personal informatics tools, International Journal of Human-Computer Studies 140, $102434 \quad$ (2020) doi: https://doi.org/10.1016/j.ijhcs.2020.102434

5. G. Fialho, A. Manhaes, J.P. Teixeira, Predicting Sports Results with Artificial Intelligence - A Proposal Framework for Soccer Games, J. Procedia Computer Science 164, 131-136 (2019) doi: https://doi.org/10.1016/j.procs.2019.12.164

6. N. Xiao, W. Yu, X. Han, Wearable heart rate monitoring intelligent sports bracelet based on Internet of things, J. Measurement 164, 108102 (2020) doi: https://doi.org/10.1016/j.measurement.2020.108102

7. R. Wang, J. Jia, Design of intelligent martial arts sports system based on biosensor network technology, J. Measurement 165, 108045 (2020) doi: https://doi.org/10.1016/j.measurement.2020.108045

8. A. Kos, Y. Wei, S. Tomazic, A. Umek, The role of science and technology in sport, J. Procedia Computer Science 129, 489-495 (2018) doi: https://doi.org/10.1016/j.procs.2018.03.029

9. P. Soltani, A. Morice, Augmented reality tools for sports education and training, J.

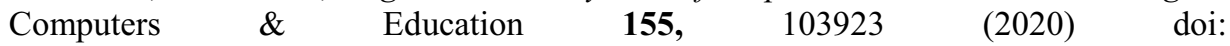
https://doi.org/10.1016/j.compedu.2020.103923

10. M.L. Brown, E. Tenison, Creation of a Dual-Purpose Collegiate Athlete Nutrition Advising Program and Educational Curriculum, J. of Nutrition Education and Behavior 50 (10), 1046-1052 (2018) doi: https://doi.org/10.1016/j.jneb.2018.07.004

11. M. Bentley, N. Mitchell, S. Backhouse, Sports nutrition interventions: A systematic review of behavioural strategies used to promote dietary behaviour change in athletes, J. Appetite 150, 104645 (2020) doi: https://doi.org/10.1016/j.appet.2020.104645

12. K.A. Rossi, Nutritional Aspects of the Female Athlete, J. Clinics in Sports Medicine 36(4), 627-653 (2017) doi: https://doi.org/10.1016/j.csm.2017.05.007

13. W. Tang, X. Shao, Q. Chen, L. Zhu, Y. He, E. Liu, Nutritional status of protein intake in severe pneumonia patients based on dietary nutrition information system, J. of Infection and Public Health (2019) doi: https://doi.org/10.1016/j.jiph.2019.07.016

14. M. Carter, A. Alwan, V. Burley, P. Wark, C. Evans, D. Greenwood, L. Hardie, G. Frost, J. Cade, Use of information and communication technology to improve dietary assessment and tackle obesity, J. The Lancet 380 (3), 529 (2012) doi: https://doi.org/10.1016/S0140-6736(13)60385-2

15. L. Berg, B. Coetzee, M. Mearns, Establishing competitive intelligence process elements in sport performance analysis and coaching: A comparative systematic literature review, International J. of Information Management 52, 102071 (2020) doi: https://doi.org/10.1016/j.ijinfomgt.2020.102071

16. H. Can, M. Lu, L. Gan, The Research on Application of Information Technology in sports Stadiums, J. Physics Procedia 22, 604-609 (2011) doi: https://doi.org/10.1016/j.phpro.2011.11.093 
17. M.D. Mifflin, S.T. Jeor, L.A. Hill, B.J. Scott, S.A. Daugherty, Y.O. Koh, A new predictive equation for resting energy expenditure in healthy individuals, Am. J. Clin. Nutr. 51, 241-247 (1990)

18. C.L. Rock, C. Doyle, W. Demark-Wahnefried, J. Meyerhardt, K.S. Courneya, A.L. Schwartz, Nutrition and physical activity guidelines for cancer survivors, $\mathrm{Ca}-\mathrm{Cancer}$ J. Clin. 62 (4), 243-274 (2012)

19. S. Thakkar, E. Anklam, A. Xu, F. Ulberth, J. Li, B. Li, M. Hugas, N. Sarma, S. Crerar, S. Swift, T. Hakamatsuka, V. Curtui, W. Yan, X. Geng, W. Slikker, W. Tong, Regulatory landscape of dietary supplements and herbal medicines from a global perspective, J. Regulatory Toxicology and Pharmacology 114, 104647 (2020). doi: https://doi.org/10.1016/j.yrtph.2020.104647

20. O.O. Borisova, Nutrition athletes: foreign experience and practical recommendations (Moscow: Soviet Sport, 2007) 